\title{
Oral health status of older people in residential homes in Saudi Arabia
}

\author{
Sharifa A. M. Al-Shehri \\ Department of Prosthetic Dental Sciences, College of Dentistry, King Saud University, Riyadh, KSA \\ Email: sharifa.a.m.alshehri@hotmail.com
}

Received 15 August 2012; revised 23 September 2012; accepted 30 September 2012

\begin{abstract}
The aim of the study was to determine the oral health status and treatment needs of elderly residents of residential homes in Riyadh, Saudi Arabia. Methods: Among 129 elderly residents, 83 (51 males, and 32 females) of them were interviewed and clinically examined according to WHO criteria by two calibrated dentists. Results: The mean age of the subjects was $72 \pm 8.5$. Male subjects had a higher smoking rate than females. Among elderly subjects below 74 years old, $20.8 \%$ had a functional dentition $(>$ or $=$ 20), while only $6.7 \%$ for those aged greater or equal to 75 years $(p=0.0004)$. Mean number of the sound teeth in all subjects was $6.7 \pm 8.5$. The mean number of DMFT was $18.6 \pm 12.6$. The missing component was the highest $(16 \pm 13)$ for both genders. The mean number of decayed roots was $2.75 \pm 3.95$ in males and $0.63 \pm 1.96$ in females. Overall, males had more sound and decayed teeth and less filled and missed teeth than females. There was no significant difference between males and females in periodontal problems except the calculus scores. The majority of subjects in need for tooth extraction were male subjects. With no gender difference $63 \%$ were in need for restorations, $\mathbf{4 0 \%}$ needed upper and lower full dentures. Need for partial dentures was $38 \%$ upper and $48 \%$ lower. Conclusion: The oral health of the institutionalized elderly population in Saudi Arabia is generally poor and their treatment needs are high.
\end{abstract}

Keywords: Older People; Oral Health Status; Residential Homes; Treatment Needs

\section{INTRODUCTION}

Oral health care for the increasing number of older residents living in nursing and elder-care homes continues to challenge caregivers, who are already overworked, to provide the necessary support for daily health maintenance. Taking into account senility due to old age, the caregivers assume overall responsibility of providing good oral care practices while continuously monitoring oral health to avoid the occurrence of dental disease [1]. Older-age people comprise a substantial portion of the population and the number is expected to increase exponentially due to changes in the life expectancy brought about by economic development in many parts of the world. The number of persons 60 years and older is expected to increase from about 670 million to almost billion worldwide by the year 2050 [2], representing a 3fold increase [2,3]. Approximately $80 \%$ of older people reside in the developed world, with the majority housed in nursing and eldercare homes. In 2010, the number of people 65 years and older in Saudi Arabia was approximately 778,000 , which represents $4 \%$ of the total population [4].

Saudi Arabia, with a population of about 21 million, is rapidly developing. In the recent past, Saudi Arabia has experienced an incredible economic escalation, which has greatly influenced the people's way of life. The percentage of the population over 60 years of age is rising and is expected to more than double by 2020, from approximately 1 million (4\% of the population) to roughly 2.5 million (7\% of the population) [5]. Although the majority of older people live independently in the community in Saudi Arabia, a growing number live in institutions. Dental caries is one of the most significant health problems facing the Saudi Arabian population. Some studies have reported that Saudi Arabian adolescents and adults have a high caries rate [6]. A literature search revealed only one study that focused on dental health problems in non-institutionalized older Saudi's [7].

The increasing population of older people will result in an increasing demand for dental care services. Extensive attention at the national level directed at oral health in children has overshadowed the concerns of older people. The lack of appropriate public health or policy interventions focusing on older people in Saudi Arabia has resulted in deterioration in their health. Thus, unless there is a paradigm shift in the dental care, older people will continue to suffer and the demand for dental care will surge [8]. 
Assessment of the oral health status and the needs of the growing number of homebound and institutionalized older people will aid in the organization of a prevention-oriented oral health care program to improve the quality for life of older people who are institutionalized. In addition, this survey will provide a good environment for a more extended and accurate nationwide study of the dental health status in older people. Dental professionals and oral health policy planners require more up-to-date and accurate information about the patterns of the disease among the elderly population to predict possible disease trends and establish plans for future goals. The aim of the present study was to determine the oral health status and treatment needs of older residents in residential homes in Saudi Arabia.

\section{RESEARCH METHODOLOGY}

In-depth interviews and clinical examinations were conducted according to the criteria of the World Health Organization (WHO) in two residential homes in Riyadh, Saudi Arabia, in June 2009. Of the 129 residents, 46 were not involved in the study, either because they did not want to participate in the study or because of various physical and mental disorders; therefore data were collected from $83(64 \%)$ residents. Information on sex, age, and assessment of coronal and root caries, periodontal disease, dental status, and related treatment needs was obtained through clinical examination. A pre-test of the clinical examination was performed by two dentists who calibrated their exams in a pilot study of 10 people who had characteristics similar to those of the study group.

Participation was voluntary and consent was obtained from all the participants before the dental examinations were performed. Findings from the screening examination were recorded on a specially prepared sheet based on the WHO health form [9]. After face-to-face interviews, the two dentists performed oral examinations. In the clinical examination, coronal decay (decayed, missing, filled teeth; DMFT) and root decay, periodontal disease (Community Periodontal Index, CPI), denture status, and related treatment needs were assessed. For functionally independent residents, the clinical examinations were performed in a dental chair using a dental operating light at the dental surgery clinic of the residential home. Functionally dependent residents were examined under artificial light in their rooms.

A CPI probe (Martin, Solingen, WHO 973/80, Germany) was used for caries diagnosis without applying pressure to dental fissures and surfaces according to WHO criteria and without radiographs. Soft and rough colored areas were recorded as caries, while hard areas were recorded as healthy. Existing restorations were also assessed for caries. Caries of the crown and root were recorded separately. The CPI was used to assess perio- dontal disease. The 10 index teeth examined were 17, 16, $11,26,27,37,36,31,46$, and 47. Each sextant that contained at least two functional teeth was assigned a code number. The condition of the most affected site in that sextant was recorded. Calculus was recorded as present or absent on the buccal, lingual (palatal), mesial, and distal tooth surfaces. Bleeding on probing was recorded as present or absent and pocket depth was measured from the free gingival margin to the base of the sulcus. Subjects were classified according to the highest code number (codes 0 - 4) assigned to any sextant of their mouth.

Denture need was assessed in accordance with the WHO assessment form as: (0) no prosthesis needed; (1) One-unit prosthesis needed (one tooth replacement) (2) Multi-unit prosthesis needed (more than one tooth replacement); (3) A combination of one- and/or multi-unit prosthesis needed; and (4) Full prostheses needed.

\section{DATA ANALYSIS}

Summary statistics were calculated to describe the characteristics of the study population and the severity of oral health problems of the participants, including the proportion, mean, median, and standard deviation for each subject, and the numbers of teeth that were sound, decayed, missing, and filled were counted. The Chi-square test or Fisher's exact test was used to compare the frequency distribution between compared groups. Because the data were not normally distributed, a non-parametric approach (Wilcoxon test) was used to compare men and women. A p-value of less than 0.05 was considered significant. All of the analyses were performed using the Statistical Package for Social Sciences (SPSS version 19, Chicago, Illinois).

\section{RESULTS}

The characteristics of the participants are presented in Table 1. There were $51 \mathrm{men}$, and 32 women, with a mean age of $72 \pm 8.5$ years. Of the 51 men, $88 \%$ were under the age of 80 years compared with $53 \%$ of the women $(p=0.0034)$. Overall, $75 \%$ of the subjects were below 80 years of age, and $25 \%$ were above 80 years $(21$ subjects). The smoking rate was higher for men than for women: $39 \%$ vs $16 \%(p=0.001)$.

The number of remaining teeth in the subjects is presented in Table 2. Subjects 74 years of age and under had more teeth than subjects 75 years and older, and men had more remaining teeth than women. Among subjects 74 years of age and under, $20.8 \%$ had more than 20 remaining teeth, while only $6.7 \%$ of those 75 years or older had more than 20 remaining teeth $(\mathrm{p}=0.0004)$. This difference was observed for both men $(24.3 \%$ vs $14.3 \%)$ and women $(12.5 \%$ vs $0.0 \%)$. A higher proportion of men than women had $\geq 20$ teeth: $11(20.8 \%)$ vs $2(6.7 \%)$. 
Table 1. Age distribution and smoking status of institutionalized older persons by sex.

\begin{tabular}{ccccc}
\hline \multirow{2}{*}{ Characteristics } & $\begin{array}{c}\text { Men }(\mathrm{n}=51) \\
\mathrm{n}(\%)\end{array}$ & $\begin{array}{c}\text { Women }(\mathrm{n}=32) \\
\mathrm{n}(\%)\end{array}$ & $\begin{array}{c}\text { Total }(\mathrm{n}=83) \\
\mathrm{n}(\%)\end{array}$ & p-value $^{*}$ \\
\hline Age & & & & \\
$<70$ & $34(66.7)$ & $13(40.6)$ & $47(56.6)$ & \\
$70-74$ & $3(5.9)$ & $3(9.4)$ & $6(7.2)$ & \\
$75-79$ & $8(15.7)$ & $1(3.1)$ & $9(10.8)$ & 0.0034 \\
$80-84$ & $3(5.9)$ & $7(21.9)$ & $10(12.0)$ & \\
$\geq 85$ & $3(5.9)$ & $8(25.0)$ & $11(13.3)$ & \\
Smoking & & & & \\
Non-smoker & $31(60.8)$ & $26(83.9)$ & $57(69.5)$ & \\
Moderate & $3(5.9)$ & $5(16.1)$ & $8(9.8)$ & 0.0010 \\
Heavy & $17(33.37)$ & $0(0.0)$ & $17(20.7)$ & \\
\hline
\end{tabular}

"Fisher's exact test.

Table 2. Distribution of remaining teeth in institutionalized elderly subjects by age and gender.

\begin{tabular}{ccccccc}
\hline \multicolumn{7}{c}{ Number of remaining teeth } \\
\hline Gender & $\begin{array}{c}\text { Age/ } \\
\text { Groups }\end{array}$ & $\leq \mathbf{4}$ & $\mathbf{5 - 1 9}$ & $\mathbf{2 0}$ & $\begin{array}{c}\text { Total, } \\
\text { n (\%) }\end{array}$ & p-value* \\
\hline \multirow{2}{*}{ Male } & $<74$ & $9(24.3)$ & $19(51.4)$ & $9(24.3)$ & $37(72)$ & 0.0376 \\
& $\geq 75$ & $9(64.3)$ & $3(21.4)$ & $2(14.3)$ & $14(28)$ & \\
\multirow{2}{*}{ Female } & $<74$ & $6(37.5)$ & $8(50.0)$ & $2(12.5)$ & $16(50)$ & 0.0382 \\
& $\geq 75$ & $13(81.3)$ & $3(18.7)$ & $0(0.0)$ & $16(50)$ & \\
\multirow{2}{*}{ Total } & $<74$ & $15(28.3)$ & $27(50.9)$ & $11(20.8)$ & $53(39)$ & 0.0004 \\
& $\geq 75$ & $22(73.3)$ & $6(20.0)$ & $2(6.7)$ & $30(61)$ & \\
\hline
\end{tabular}

*From Fisher's exact test.
The dental status of older people in the Riyadh institutions is shown in Table 3. Mean number of the sound teeth in all subjects was $6.7 \pm 8.5( \pm \mathrm{SD})$. Men had more teeth than women (mean: men, 8.2; women, 4.3 ). The total number of decayed teeth was 146 in men and 36 in women, translating to a mean of $2.9 \pm 3.8$ in men and $1.1 \pm 2.9$ in women $(\mathrm{p}=0.0018)$. Of 1336 missing teeth, 605 were recorded in men (mean $11.9 \pm 12.5$ ) compared to 731 in women $(22.8 \pm 11.2)$. The total number of DMFT was 1545, 754 for men and 791 for women. Mean number of DMFT was $17.8 \pm 12.6$ in men and $24.7 \pm 10.0$ in women. Mean number of decayed roots was $2.8 \pm 4.0$ in men and $0.6 \pm 2.0$ in women. The men had 3 filled teeth compared to 24 in women with a mean of $0.1 \pm 0.3$ in men and $0.8 \pm 1.8$ in women. Overall, men had more sound and decayed teeth, and fewer filled and missing teeth than women. Smokers had significantly higher DMFT scores than non-smokers (Table 4).

Assessment of the periodontal status based on the CPI scores indicated that only 7 subjects showed six sextants with healthy periodontal status. The incidence of periodontal problems did not differ significantly between men and women, except for calculus scores $26(51 \%)$ in men, $9(28.1 \%)$ in women indicating that women may have better oral hygiene (Table 5).

There were $33.7 \%$ subjects who needed one surface filling, while an additional $28.9 \%$ required two or more surface fillings, and $48.2 \%$ needed to undergo a tooth extraction. Men comprised the majority of people requiring a tooth extraction (68.6\%; Table 6).

Table 3. Summary statistics of dental status in institutionalized older persons by sex.

\begin{tabular}{|c|c|c|c|c|}
\hline Dental status & Men & Women & Total & p-value* \\
\hline Number of sound teeth (n) & 419 & 136 & 555 & \multirow{4}{*}{0.0635} \\
\hline Mean \pm SD & $8.2 \pm 9.3$ & $4.3 \pm 6.4$ & $6.7 \pm 8.5$ & \\
\hline Median & 5 & 1 & 3 & \\
\hline Minimum - Maximum & $0-31$ & $0-23$ & $0-31$ & \\
\hline Number of decayed teeth (crown) (n) & 146 & 36 & 182 & \multirow{4}{*}{0.0018} \\
\hline Mean $\pm \mathrm{SD}$ & $2.9 \pm 3.8$ & $1.1 \pm 2.9$ & $2.2 \pm 3.6$ & \\
\hline Median & 2 & 1 & 1 & \\
\hline Minimum - Maximum & $0-17$ & $0-12$ & $0-17$ & \\
\hline Number of missed teeth (crown) (n) & 605 & 731 & 1336 & \multirow{4}{*}{0.0003} \\
\hline Mean $\pm \mathrm{SD}$ & $11.9 \pm 12.5$ & $22.8 \pm 11.2$ & $16.1 \pm 13.1$ & \\
\hline Median & 5 & 29 & 14 & \\
\hline Minimum - Maximum & $0-32$ & $0-32$ & $0-32$ & \\
\hline Total number of DMFT (n) & 754 & 791 & 1545 & \multirow{4}{*}{0.0012} \\
\hline Mean \pm SD & $17.8 \pm 12.6$ & $24.7 \pm 10.0$ & $18.6 \pm 12.6$ & \\
\hline Median & 13 & 31 & 21 & \\
\hline Minimum - Maximum & $0-32$ & $0-32$ & $0-32$ & \\
\hline Number of decayed (root) (n) & 140 & 20 & 160 & \multirow{4}{*}{0.0002} \\
\hline Mean \pm SD & $2.8 \pm 4.0$ & $0.6 \pm 2.0$ & $19.3 \pm 3.5$ & \\
\hline Median & 1 & 0 & 0 & \\
\hline Minimum - Maximum & $0-18$ & $0-10$ & $0-18$ & \\
\hline Total number of filled (n) & 3 & 24 & 27 & \multirow{4}{*}{0.008} \\
\hline Mean $\pm \mathrm{SD}$ & $0.1 \pm 0.3$ & $0.8 \pm 1.8$ & $0.3 \pm 1.2$ & \\
\hline Median & 0 & 0 & 0 & \\
\hline Minimum - Maximum & $0-2$ & $0-8$ & $0-8$ & \\
\hline
\end{tabular}

*From the Wilcoxon test. 
Table 4. Comparison of DMFT scores between smokers and non-smokers.

\begin{tabular}{cccccc}
\hline \multirow{2}{*}{ Sex } & \multicolumn{2}{c}{ Smokers } & \multicolumn{2}{c}{ Non-smokers } & \multirow{2}{*}{ p-value $^{*}$} \\
\cline { 2 - 5 } & $\mathbf{n}$ & Mean $\pm \mathbf{S D}$ & $\mathbf{n}$ & Mean \pm SD & \\
\hline Men & 20 & $13.85 \pm 3.4$ & 32 & $10.56 \pm 5.52$ & 0.012 \\
Women & 5 & $15.60 \pm 0.54$ & 25 & $12.88 \pm 4.65$ & 0.008 \\
Total & 25 & $14.20 \pm 3.12$ & 57 & $11.52 \pm 5.25$ & 0.006 \\
\hline
\end{tabular}

${ }^{*}$ Based on a two sample independent t-test.

Table 5. Distribution of periodontal status (CPI score) of institutionalized older persons by sex.

\begin{tabular}{ccccc}
\hline & Men n (\%) & Women n (\%) & Total n (\%) & p-value \\
\hline Sound & \multicolumn{4}{c}{ Periodontal status (CPI score): } \\
Bleeding on probing & $7(13.7)$ & $3(9.4)$ & $7(8.4)$ & 0.807 \\
Calculus & $26(51.0)$ & $9(28.1)$ & $15(18.1)$ & 0.194 \\
Shallow pockets & $10(19.6)$ & $5(15.6)$ & $15(18.1)$ & 0.040 \\
Deep pockets & $1(2.0)$ & $0(0.0)$ & $1(1.2)$ & 0.646 \\
\hline
\end{tabular}

Table 6. Distribution of treatment needs in institutionalized older persons by sex.

\begin{tabular}{ccccc}
\hline Treatment needs & Men $(\mathbf{n}=\mathbf{5 1}) \mathbf{n}(\mathbf{\%})$ & Women $(\mathbf{n}=\mathbf{3 2}) \mathbf{n}(\mathbf{\%})$ & Total $(\mathbf{n}=\mathbf{8 3}) \mathbf{n}(\mathbf{\%})$ & $\mathbf{p}$-value \\
\hline One surface filling & $21(41.2)$ & $7(21.9)$ & $28(33.7)$ & 0.070 \\
Two or more surface fillings & $18(35.3)$ & $6(18.8)$ & $24(28.9)$ & 0.106 \\
Extraction & $35(68.6)$ & $5(15.6)$ & $40(48.2)$ & $<0.0005$ \\
\hline
\end{tabular}

Table 7 shows the prosthetic status and need. For the upper jaw, there were $87 \%(\mathrm{n}=72)$ without a prosthesis, $6 \%$ with a full removable $(\mathrm{n}=5)$ prostheses, and $7.4 \%$ $(\mathrm{n}=6)$ with at least 1 bridge. Men and women had a similar distribution $(\mathrm{p}=0.6905)$. Similar to the upper jaw, the majority $(93 \%)$ of subjects had no prostheses for the lower jaw, while $4.8 \%$ had a bridge and $2.4 \%$ had a full lower denture.

The distribution was not different between men and women $(p=0.3302)$. Table 7 shows the distribution of prosthetic needs. For the upper jaw, approximately 38\% required multi-unit prostheses, and $44 \%$ required a full prosthesis. Though the overall comparison was not significant $(\mathrm{p}=0.1306)$, men tended to have a slightly higher need than women for multi-unit prostheses $(42 \%$ vs $31 \%$ ) and for a combination of multi-unit and full prostheses $(10 \%$ vs $0 \%)$. Men had a slightly lower need for full prostheses than women (36\% vs 56\%).

A similar distribution pattern was observed for the lower jaw. The higher needs were for multi-unit bridges $(48 \%)$ and full prostheses (40\%). Men had slightly higher needs for multi-unit bridges than women (54\% vs $39 \%$ ) and lower needs for full prostheses ( $32 \%$ vs $52 \%$ ). In addition, $6.0 \%$ of men and $3.2 \%$ of women did not require a prosthetic for their lower jaws.
Table 7. Prosthetic status and need in institutionalized older persons by sex.

\begin{tabular}{|c|c|c|c|c|}
\hline & $\begin{array}{c}\text { Men } \\
\text { N }(\%)\end{array}$ & $\begin{array}{c}\text { Women } \\
\text { N (\%) }\end{array}$ & $\begin{array}{c}\text { Total } \\
\text { N (\%) }\end{array}$ & p-value* \\
\hline \multicolumn{5}{|l|}{ Prosthetic status: upper } \\
\hline No prosthetic & $45(88.2)$ & $27(84.4)$ & $72(87)$ & 0.6905 \\
\hline Bridge & $3(5.9)$ & $1(3.1)$ & $4(5)$ & \\
\hline More than one bridge & $1(2.0)$ & $1(3.1)$ & $2(2.4)$ & \\
\hline Full removable & $2(3.9)$ & $3(9.4)$ & $5(6.0)$ & \\
\hline \multicolumn{5}{|l|}{ Prosthetic status: lower } \\
\hline No prosthetic & $49(96)$ & $28(87.5)$ & $77(93)$ & 0.3302 \\
\hline Bridge & $1(2.0)$ & $3(9.4)$ & $4(4.8)$ & \\
\hline Full removable & $1(2.0)$ & $1(3.1)$ & $2(2.4)$ & \\
\hline \multicolumn{5}{|l|}{ Prosthetic need: upper } \\
\hline No need & $5(10.0)$ & $2(6.2)$ & $7(8.5)$ & 0.1306 \\
\hline One unit & $1(2.0)$ & $2(6.2)$ & $3(3.7)$ & \\
\hline Multi-unit & $21(42.0)$ & $10(31)$ & $31(38)$ & \\
\hline combination & $5(10.0)$ & 0 & $5(6.1)$ & \\
\hline full & $18(36.0)$ & $18(56)$ & $36(44)$ & \\
\hline \multicolumn{5}{|l|}{ Prosthetic need: lower } \\
\hline No need & $3(6.0)$ & $1(3.2)$ & $4(4.9)$ & 0.0611 \\
\hline One unit & 0 & $2(6.5)$ & $2(2.5)$ & \\
\hline Multi-unit & $27(54.0)$ & $12(39)$ & $39(48)$ & \\
\hline combination & $4(8.0)$ & 0 & $4(4.9)$ & \\
\hline full & $16(32.0)$ & $16(52)$ & $32(40)$ & \\
\hline
\end{tabular}

*From Fisher's exact test. 


\section{DISCUSSION}

The findings of the present study established that oral health care screening is imperative and effective, particularly for the identification and assessment of dental needs and oral health status of older people in residential homes. Although the present study has some limitations, such as evaluation of institutionalized older people in only one major city with higher economic status and better levels of health care services, the findings warrant further studies including residential homes in several cities throughout Saudi Arabia to provide a reliable and holistic picture of the oral health status in the country. Additionally, the lack of demographic information for those residents who did not participate in the study makes it difficult to estimate the magnitude of the selection bias.

The group of subjects included in the present study was not presumed to be representative of the entire senior adult Saudi population, but our aim was to investigate and report oral health status and its indicators in a convenient sample of institutionalized Saudi elderly. The data revealed that most of the older people in two residential homes were under 70 years of age, mainly due to the moderate life expectancy and the social norm that the majority of older people are taken care of by the community.

Severe dental caries and periodontal disease are the major reasons for tooth extraction [10-12]. In this study, caries was the primary cause of tooth loss. Additionally, heavy smokers had higher DMFT scores than nonsmokers, consistent with the findings of Jette et al. [13] and Morita et al. [14], who reported that tobacco use is a risk factor for tooth loss, particularly among people with a high consumption over many years.

The number of teeth remaining in older people serves as a measure of oral health. The functionality of subject dentition depicted by the number of retained teeth at the age of 75 years and above was a low value (6.7\%) among subjects. These results are very close to those reported for older Turkish institutionalized subjects [15]. In contrast, in Germany and Denmark $29 \%$ and $40 \%$ of older people, respectively, retain more than 20 teeth, particularly at the age of 75 and above. This improvement is thought to result from the continuous and regular utilization of dental care services, especially preventive therapy and specialized treatment $[16,17]$.

The mean number of sound teeth present in the older people was 6.7 in this study compared to 13.8 in Australia (Saub \& Evans) [8] and 3.7 in Turkey (Unluer et al.) [15]. Some similarities were observed in the mean number of decayed teeth: 2.2 in both this study and in Turkey [15]. Great variations were observed in the number of missing teeth, however, with our study showing a mean of 16.1 in contrast with 28.2 in Turkey [15]. These dis- crepancies could be due to the lower mean age of the current population and the relative accessibility and availability of dental care services in Saudi Arabia.

The prevalence of caries as expressed in terms of DMFT was 18.6, of which the missing component comprised 16.10. This score was higher for non-institutionalized older Saudi patients reported by Zahrani [7]. Turkish [15], Australian [8], and Spanish [18] studies reported values of 28.2, 24.7, and 25.1, respectively. The figures were slightly higher, however, compared with those in non-institutionalized older people in other countries. For example, DFMT levels are 13.5 in India [19] and 12.5 in China [20].

The high missing component of the DMFT score for older people could be related to the belief in some communities that tooth extraction is considered by many to be the most acceptable treatment for dental disease [21, 22]. It is presumed that the increase in edentulism and denture demand implies that all preventive measures were inadequate and that secondary restorative measures also failed, which represents a major weakness in the dental care system.

The decreased number of remaining teeth in the older people leads to lower numbers of filled and decaying teeth as people age. It is worth noting, therefore, that as more adults retain their teeth into advanced old age, the risk of contracting dental disease increases and therefore the need for dental care services for the older people also increases [23].

Mean number of untreated dental caries in our study sample was 2.2 and the mean number of restored teeth was 0.3 , consistent with reports from other developed countries. In China, the second national oral health survey revealed that the mean number of decayed and filled teeth was 2.5 at old age [20], and a study in India also reported a mean number of decayed teeth of 2.5 [19]. In a recent survey of 65 to 74-year-olds in Madagascar [24], the mean DMFT score was 20.2; untreated dental caries was high $(\mathrm{DT}=5.3)$, whereas the number of restored teeth was low $(\mathrm{FT}=0.4)$. On the other hand, a study carried out in Australia on people aged 70 years and over [8] indicated that the mean number of filled teeth was 8.3 per subject for coronal caries.

In the present study, men had more caries, but fewer filled teeth, than women and these results are similar to those of other studies $[7,15,25]$. The relatively high percentage of filled teeth observed among women suggests that women are more aware of their dental problems. Unlike in the Turkish study [15], the prevalence of root caries was higher in men than in women, consistent with the report by Alzahrani for non-institutionalized Saudis [7].

We were surprised to find almost no deep pockets in our study sample and this finding indicates a probable 
sample selection bias toward healthy subjects. Shallow pocketing was slightly higher $(18.1 \%)$ compared to the report by Ulner et al. study [15] in Turkey (10.2\%). A slight difference was also observed in the CPI scores on bleeding on probing with our finding of $18.1 \%$ compared to $22.4 \%$ [15].

The prevalence of calculus in subjects of the present study was $42.2 \%$, with $51 \%$ in men and $28.1 \%$ in women. The prevalence of calculus is an indication of the level of oral hygiene and the frequency of continuous regular dental care, especially in this particular population. Similar findings were reported for studies of non-institutionalized subjects [7]. The results, however, were substantially lower than the $82 \%$ reported in the UK by Frenkel et al. [26].

Treatment needs were generally higher in men than in women, but the difference was not significant except in regard to the need for extraction. Men had more badly decayed teeth and hopeless retained roots than women. Generally, the need for tooth extraction was very high, i.e., almost half of the subjects, consistent with previous studies performed in Athens [27]. The present study also showed higher percentages of teeth requiring extraction compared to the findings of Peltola et al. [23], who reported that $42 \%$ of dentate subjects needed extraction, and compared to Saub and Evans [8], who reported that $20 \%$ of dentate subjects required extraction due to dental caries and periodontal disease. In the present study, $63 \%$ of the dentate subjects required at least one restoration. Saubs and Evans reported similar characteristics, with $64 \%$ of their study sample requiring at least one restoration [8].

Remarkably, the majority of subjects $(87 \%$ for the upper jaw and $93 \%$ for the lower) were able to function without prosthetic replacement of the missing teeth despite the high need for multi-unit bridges or full dentures ( $82 \%$ for the upper jaw and $88 \%$ for the lower jaw). The shortened dental arch in partially edentate subjects could be a reason for the adequate function despite the lack of a prosthetic replacement. Compared with other studies, the older subjects in the present study had undergone more extractions and fewer restorative treatments. Nearly $100 \%$ of the utilization of restorative dental treatments, such as prosthetics and dentures, has been recorded in institutionalized older people, particularly in studies performed in Finland [28]. The absence of prosthetic replacement for missing teeth $(93 \%$ of subjects with missing teeth) was much higher than that $(50 \%)$ in Australia reported by Saub and Evans. Compared to the $2.4 \%$ of subjects with full lower dentures in this study, $16 \%$ of the subjects wore full lower dentures in the Australian study [8].

Relatively few epidemiologic studies of tooth loss at old age have been conducted in developing countries. In the developing countries, however, access to oral health services is limited and teeth are often extracted because of pain or discomfort, or because of the lack of materials needed for dental treatment.

Further research in this field is needed to help acquire precise data and information vital for directing policy changes in public institutions in Saudi Arabia. Particularly important are the implications for the provision of affordable preventive therapy and treatment methods aimed at improving the overall quality of the oral health and life of older people. The study findings provide a general overview on the oral health status and the management of dental diseases for older people living in residential institutions in Saudi Arabia. These findings provide information vital to the dental profession, researchers, and patients, and describe avenues for divergent approaches to oral management while providing the required guidance.

\section{CONCLUSION}

The oral health of the institutionalized elderly population in Saudi Arabia is generally poor, based on the high number of cases of decaying and missing teeth, and the need for medical intervention. There is an urgent need to persuade people to adopt preventive therapy while also seeking medical interventions to enhance the retention of natural teeth into advanced age. Policy changes are required to entrench the development of oral health care services into the overall health plan of institutions hosting older people. The ministry of health in Saudi Arabia should make oral health care services more accessible and affordable to older people by introducing flexible programs that will allow geriatric specialists to visit eldercare residential homes. Provision of oral health care to older people will not only lead to economic savings but will also reduce the work burden of the caregivers.

\section{ACKNOWLEDGEMENTS}

This study was approved by the Ethical Review Committee of the College of Dentistry Research Center (CDRC), King Saud University. Permission from the authorities in the Ministry of Social Affairs and the direct authorities in the elderly institutions included in the study was also obtained.

The author expresses her deepest appreciation to Dr. Noura Alsaif from the Department of Oral Medicine and Diagnostic Science, College of Dentistry, King Saud University, for her assistance in interviewing and examining the older people who participated in this study.

\section{REFERENCES}

[1] Stubbs C. and Riordan P.J. (2002) Dental screening of older adults living in residential aged care facilities in Perth. Australian Dental Journal, 47, 321-326. 


\section{doi:10.1111/j.1834-7819.2002.tb00545.x}

[2] United Nations Population Division (2003) World population prospects: The 2002 revision. United Nations, New York.

[3] World Health Organization (2002) Active ageing: A policy framework. WHO, Geneva.

[4] Central Intelligence Agency (2011) The world factbook. Saudi Arabia.

https://www.cia.gov/library/publications/the-world-factbo ok/geos/sa.html

[5] World Health Organization (WHO) (2012) WHO Oral Health Country/Area Profile. Saudi Arabia. http://www.fluentfactory.com/mboxmail

[6] Al-Shammary, A.R., Guile, E. and El-Backly, M. (1981) An oral health survey of Saudi Arabia. Phase I (Riyadh). King Abdul Aziz City for Science and Technology Riyadh, Riyadh.

[7] AL-Zahrani, A. (2005) Dental health status among a sample of elderly dental patients in Riyadh, Saudi Arabia. Saudi Dental Journal, 17, 74-82.

[8] Saub, R. and Evans, R.W. (2001) Dental needs of elderly hostel residents in inner Melbourne. Australian Dental Journal, 46, 198-202. doi:10.1111/j.1834-7819.2001.tb00282.x

[9] World Health Organization (1997) Oral health surveysBasic methods. 4th Edition, WHO, Geneva, 21-52.

[10] Schou, L. (1995) Oral health, oral health care, and oral health promotion among older adults: Social and behavioral dimensions. In: Cohen, L.K. and Gift, H.C., Eds. Disease Prevention and Oral Health Promotion, Munksgaard, Copenhagen, 213-270.

[11] Morita, M., Kimura, T., Kanegae, M., et al. (1994) Reasons for extraction of permanent teeth in Japan. Community Dentistry and Oral Epidemiology, 22, 303-306. doi:10.1111/j.1600-0528.1994.tb02056.x

[12] Shimazaki, Y., Soh, I., Koga, T., et al. (2003) Risk factors for tooth loss in the institutionalised elderly; a sixyear cohort study. Community Dental Health, 20, 123127.

[13] Jette, A.M., Feldman, H.A. and Tennstedt, S.L. (1993) Tobacco use: A modifiable risk factor for dental disease among the elderly. American Journal of Public Health, 83, 1271-1276. doi:10.2105/AJPH.83.9.1271

[14] Morita, I., Nakagaki, H., Toyama, A., et al. (2006) Behavioral factors to include in guidelines for lifelong oral healthiness: An observational study in Japanese adults. BMC Oral Health, 6, 15. doi:10.1186/1472-6831-6-15

[15] Unluer, S., Gokalp, S. and Dogan, B. (2007) Oral health status of the elderly in a residential home in Turkey. Gerodontology, 24, 22-29. doi:10.1111/j.1741-2358.2007.00136.x
[16] Mack, F., Mundt, T., Mojon, P., et al. (2003) Study of health in Pomerania (SHIP): Relationship among socioeconomic and general health factors and dental status among elderly adults in Pomerania. Quintessence International, 34, 772-778.

[17] Christensen, L.B., Petersen, P.E., Krustrup, U., et al. (2003) Self-reported oral hygiene practices among adults in Denmark. Community Dent Health, 20, 229-235.

[18] Spanish Geriatric Oral Health Research Group (2001) Oral health issues of Spanish adults aged 65 and over. International Dental Journal, 51, 228-234.

[19] Thomas, S., Raja, R.V., Kutty, R., et al. (1994) Pattern of caries experience among an elderly population in South India. International Dental Journal, 44, 617-622.

[20] Wang, H.-Y., Petersen, P.E., Bian, J.-Y., et al. (2002) The second national survey of oral health status of children and adults in China. International Dental Journal, 52, 283-290. doi:10.1111/j.1875-595X.2002.tb00632.x

[21] Kalsbeek, H., Truin, G.J., Burgersdijk, R., et al. (1991) Tooth loss and dental caries in Dutch adults. Community Dentistry and Oral Epidemiology, 19, 201-204. doi:10.1111/j.1600-0528.1991.tb00146.x

[22] Soh, G., Chong, Y.H. and Ong, G. (1992) Dental state and needs for episodic care of institutionalized elderly in an Asian community. Social Science \& Medicine, 34, 415-418. doi:10.1016/0277-9536(92)90301-6

[23] Peltola, P., Vehkalahti, M.M. and Wuolijoki-Saaristo, K. (2007) Oral health and treatment needs of the long-term hospitalised elderly. Gerodontology, 21, 93-99. doi:10.1111/j.1741-2358.2004.00012.x

[24] Petersen, P.E., Razanamihaja, N. and Poulsen, V.J. (2004) Surveillance of oral health among children and adults in Madagascar. WHO, Geneva.

[25] Hämäläinen, P., Meurman, J.H., Keskinen, M., et al. (2004) Changes in dental status over 10 years in 80-yearold people: A prospective cohort study. Community Dentistry and Oral Epidemiology, 32, 374-384. doi:10.1111/j.1600-0528.2004.00178.x

[26] Frenkel, H., Harvey, I. and Newcombe, R. (2000) Oral health care in nursing home residents in Avon. Gerodontology, 17, 33-38. doi:10.1111/j.1741-2358.2000.00033.x

[27] Karkazis, H.C. and Kossini, A.E. (1993) Oral health status, treatment needs and demands of an elderly population in Athens. European Journal of Prosthodontics and Restorative Dentistry, 1, 157-163.

[28] Pajukoski, H., Meurman, J.H., Snellman-Gröhn, S., et al. (1999) Oral health in hospitalized and non-hospitalized community-dwelling elderly patients. Oral Surgery, Oral Medicine, Oral Pathology, Oral Radiology, and Endodontology, 88, 437-443. doi:10.1016/S1079-2104(99)70058-2 